\title{
European drought regimes under mitigated and unmitigated climate change: application of the Community Integrated Assessment System (CIAS)
}

\author{
R. Warren ${ }^{1, *}$, R. M. S. Yu ${ }^{1}$, T. J. Osborn ${ }^{2}$, S. de la Nava Santos ${ }^{1}$ \\ ${ }^{1}$ Tyndall Centre and ${ }^{2}$ Climatic Research Unit, School of Environmental Sciences, University of East Anglia, \\ Norwich NR4 7TJ, UK
}

\begin{abstract}
Climate change is expected to cause significant changes in the future distribution of precipitation, as well as in the frequency and intensity of high and low rainfall events across the world. In particular, there is an expectation of drying in southern Europe and wetting in northern Europe, with some regions such as southern UK experiencing drier summers and wetter winters. In this study, a community integrated assessment system (CIAS) is used to project the impacts of climate change associated with various emissions scenarios and in particular to demonstrate the extent to which climate mitigation policy might reduce the projected changes in drought regime for Europe under climate change scenarios over the 21st century. Components of CIAS include a simple climate model, MAGICC, and a spatial climate scenario generator, ClimGen, tuned to emulate 3 global general circulation model behaviours and climate change patterns. In baseline (no mitigation policy) cases, very large increases in drought are projected for southern Europe. However, stringent mitigation policy, in which $\mathrm{CO}_{2}$ concentrations stabilize at 450 or $400 \mathrm{ppm}$, produces very large reductions in both drought frequency and in total months of drought which would otherwise be experienced during 2050 to 2099, regardless of the global circulation model used to project the patterns of climate change across Europe. The study also illustrates a possible range of future drought scenarios which adaptation planners across Europe need to consider.
\end{abstract}

KEY WORDS: Drought · Climate change - Integrated assessment modelling · Climate mitigation · Adaptation $\cdot$ Climate variability

Resale or republication not permitted without written consent of the publisher

\section{INTRODUCTION}

Climate change will influence not only mean climates but also climate variability, including the frequency and intensity of drought (Blenkinsop \& Fowler 2007a,b). A key question, therefore, is to what extent modeling studies can provide information on future drought scenarios for policy makers. In particular, an adaptation planner will need to know the potential range of future drought frequency and intensity that may result from climate change, in both the presence and absence of climate mitigation policies. Further, the mitigation planner needs to know the extent to which climate mitigation policies are effective in preventing the future changes in drought regime which might otherwise result.

UKCIP02 (Hulme et al. 2002) provided future scenarios of UK drought, based only on a single global circulation model (GCM), HadCM3. Recent studies (Blenkinsop \& Fowler 2007a,b, Frei et al. 2006, Beniston et al. 2007) have examined the future changes in European and UK drought characteristics projected by a range of PRUDENCE ${ }^{1}$ regional climate models

\footnotetext{
${ }^{1}$ The European Union project 'Prediction of Regional scenarios and Uncertainties for Defining European Climate change risks and Effects' (PRUDENCE) presented the first comprehensive continental-scale intercomparison and evaluation of high resolution climate models and their applications
} 
(Christensen et al. 2007) driven by 2 alternative GCMs . Blenkinsop \& Fowler $(2007$ a,b) and Frei et al. (2006) projected future changes in drought characteristics based on the SRES A2 emissions scenario only (Nakicenovich \& Swart 2000) whilst Beniston et al. (2007) used A2 and B2 SRES scenarios. Lehner et al. (2006) simulated future European drought using a model named WaterGAP driven by the inputs of 2 alternative GCM patterns from HadCM3 and ECHAM4, considering 2 no-climate policy baselines including IS92a in which $\mathrm{CO}_{2}$ concentrations increase by $1 \%$ annually (IPCC 1994). Ensemble-based probabilistic projections exist for changes in European extreme precipitation (Palmer \& Ralsanen 2002) for the period 20602080, again for IS92a, and for daily precipitation and hydrology in the UK (New et al. 2007) for doubled $\mathrm{CO}_{2}$ concentrations. Recent global, but regionally specific, studies have improved on these earlier studies by using a wider range of GCMs (Sheffield \& Wood 2008; Hirabayashi et al. 2008, Planton et al. 2008) but focus on 1 to 3 emissions scenarios only. None of these studies examine the implications of higher emissions of the SRES A1 fossil intensive scenario (A1FI).

The present study builds on this existing work by (1) including, for the first time, the study of scenarios which include climate policy (i.e. policy-induced reductions in emissions of greenhouse gases, commonly referred to as mitigation); (2) calculating, for the first time, the benefits of the mitigation: specifically, by quantifying the reductions in projected European drought in a climate policy scenario compared to a no-climate policy scenario; (3) increasing the number of studies which use several alternative GCM patterns of climate change; (4) assessing the implications of a fossil-intensive future energy system.

Overall, the study provides a directly policy-relevant estimate of projected drought across a range of SRES scenarios and potential climate policy (i.e. mitigation) scenarios, using 3 different GCM patterns.

\section{METHODS}

We used the Community Integrated Assessment System (CIAS) model (Warren et al. 2008) to examine the implications of various future climate change scenarios. The pattern scaling (down-scaling) model ClimGen (developed from Mitchell et al. 2004; see also Warren et al. 2008; Osborn 2009) is a key component of CIAS relevant to this project, and we postprocessed the output of this model to project the frequency and the length of drought events in the 21st century in Europe.

\subsection{CIAS model}

CIAS is a unique multi-institutional modular and flexible integrated assessment system for modelling climate change. This is a deterministic simulation model, and thus its main application is to compare different future scenarios of the world. Uniquely, CIAS is supported by a framework SoftIAM which allows various combinations of component codes, known as modules, to be connected together into alternative integrated assessment models. Modules in CIAS currently include an emulator of the outputs of E3MG, a global energy-environment-economy module, including a representation of induced technological change (Barker et al. 2006); an emissions scenario converter (ESM) which provides either emissions scenarios used in the IPCC assessments, or emissions scenarios directly from E3MG; a global simple climate module (SCM), MAGICC, from the University of East Anglia (Wigley \& Raper 2001); a spatial climate scenario generator (SCSG), ClimGen, also from the University of East Anglia (Osborn 2009); and various climate impacts modules representing hydrology (Arnell 2004), coastal impacts (DIVA: http:// www.pik-potsdam.de/research/transdisciplinaryconcepts-and-methods/projects/project-archive/ favaia/diva) and biome shifts (Fussel 2003). The user of CIAS is able to determine the particular CIAS coupled model they wish to use through a web portal. Fig. 1 illustrates the CIAS coupled model used in our study, which links together the E3MG_ESM/IPCC_ ESM with the SCM and the SCSG. The underlying computational infrastructure (the Bespoke Framework Generator) is contributed by the Centre for Novel Computing at the University of Manchester.

\subsection{Emissions scenarios}

Two sets of emissions scenarios were selected for study, the Special Report on Emission Scenarios (SRES) and stabilization scenarios.

\subsubsection{SRES scenarios}

These are described in the Special Report on Emission Scenarios (SRES) of the Intergovernmental Panel on Climate Change (Nakicenovich \& Swart 2000). They are structured in 4 major 'families' labeled A1, $\mathrm{A} 2$, B1 and B2. In the ' $\mathrm{A}$ ' scenarios, society is more economically oriented, and in ' $\mathrm{B}$ ' scenarios more environmentally oriented in the future. Family ' 1 ' sce- 


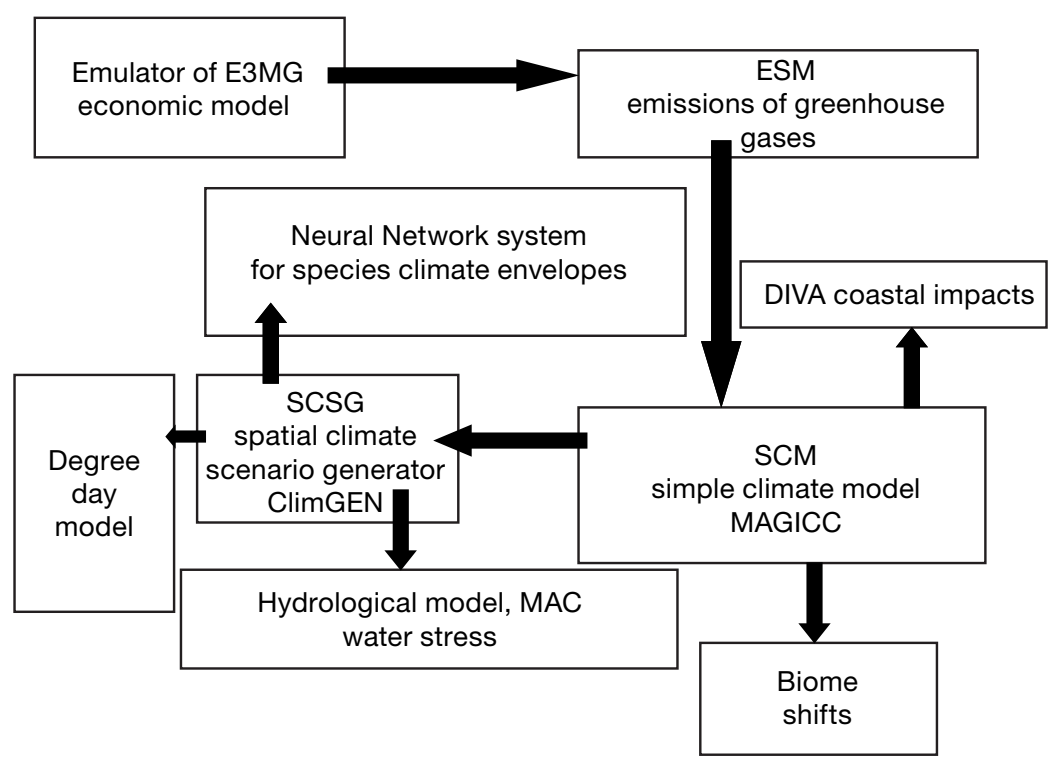

Fig. 1. Community Integrated Assessment System (CIAS) climate model component can, with appropriate tuning of its parameters, emulate several different different atmosphere-ocean global circulation models (AOGCMs). The tuning process typically involves optimization of $3 \mathrm{key}$ parameters to best reproduce the scenarios in which forcing increases by $1 \%$ per yr over the 21 st century, and further refinements to other parameters (Meinshausen et al. 2008).

The feedback between climate and the carbon cycle means that the relationship between $\mathrm{CO}_{2}$ emissions and atmospheric concentrations depends on the global-mean temperature change, and thus also on the parameter values of the MAGICC climate model component. The emissions scenarios are described in Barker et al. (2006) and are set so that with the SCM tuned to the HadCM3 GCM, concentrations of $\mathrm{CO}_{2}$ in the atmosphere stabilize by 2100 at approximately 450, 500, and 550 ppm, without 'overshooting' the concentration ceiling before stabilization (Figs. S3 \& S4). Only small associated reductions in emissions of $\mathrm{CH}_{4}$ and $\mathrm{N}_{2} \mathrm{O}$ are included. A more extreme scenario which stabilizes $\mathrm{CO}_{2}$ concentrations at $400 \mathrm{ppm}$ is also included, in which emissions of $\mathrm{CH}_{4}$ and $\mathrm{N}_{2} \mathrm{O}$ are artificially set to zero in 2010. Figs. S3 \& S4 show the $\mathrm{CO}_{2}$ emissions and atmospheric concentrations over the 21st century in each of these 4 scenarios. Figs. S5 to S10 show annual global mean temperature rise, and emissions and atmospheric concentrations of methane and nitrous oxide for each of the 5 SRES scenarios and 4 stabilization scenarios described above.

\subsection{ClimGen component}

The currently available spatial climate scenario generator (SCSG) is ClimGen, a tool for generating fields of climate data using the method of pattern scaling, and thus in the tradition of CLIMAPS (Rotmans et al. 1994), SCENGEN (Hulme et al. 1995), CLIMPACTS (Kenny et al. 1995) and COSMIC (1997). ClimGen was developed from methods already described in Mitchell et al. (2004), and Goodess et al. (2003); Osborn (2009) provides information on its use. Here, we use version 1-00 of ClimGen. This version provides month-by-month climate variations for both observed climate from 1901 to 2002 (CRU TS 2.1, Mitchell \& Jones, 2005), and future cli-
The MAGICC SCM combines an energy-balance climate model with gas cycle models for the main greenhouse gases, including the carbon cycle. The 
mate scenarios over 2001 to 2100 (Mitchell et al. 2004 ), at a resolution of $0.5^{\circ}$ latitude by $0.5^{\circ}$ longitude, for the entire terrestrial land surface except Antarctica. Climate fields can be generated for 8 climate variables based on GCM outputs, specifically: mean, maximum and minimum temperature; precipitation, vapour pressure, cloud cover, and wet day frequency. Annual, monthly or seasonal outputs may be produced and outputs may be averaged over a time slice of a length selected by the user.

For version 1-00 of ClimGen, the linear relationship between grid-box climate change and global-mean temperature change $(\Delta T)$ was diagnosed by simple regression using simulations from 5 GCMs (HadCM3, CSIRO2, ECHAM4, PCM2 and CGCM2), each run with up to 4 SRES scenarios ${ }^{2}$, providing 13 different GCM patterns. Hence, 13 alternative time series of regional monthly climate can be generated to sample the range of uncertainty. Deviations from the linear relationships between grid-box climate change and $\Delta T$, and thus a breakdown of the main assumption underlying the use of pattern scaling, are most apparent when scaling from a pattern diagnosed from a simulation with a slowly changing climate to estimate the pattern expected in response to a more rapidly changing climate (Mitchell 2003), or between scenarios with greatly differing sulphate aerosol forcing. Patterns diagnosed from simulations with the same GCM but under different forcing scenarios are, therefore, provided in ClimGen, so that the most appropriate one can be selected (e.g. use the B2 pattern for a CIAS experiment in which the rate of climate forcing increases relatively slowly).

The patterns of regression coefficients (Mitchell 2003) were diagnosed on the original grid of each GCM, and then interpolated using distance-weighted averaging to a higher resolution of $0.5 \times 0.5^{\circ}$. These interpolated patterns of change per degree Kelvin of global warming $\left(p_{\text {gvmi }}\right)$, diagnosed from each GCM simulation $(g)$ and available for 8 variables $(v)$ and for each month of the year $(m)$ at each grid box $(i)$, form the main ClimGen database. For any given change in global-mean temperature simulated within CIAS (e.g. via the MAGICC SCM), ClimGen generates a pattern of mean climate change from the product $p_{\text {gvmi }} \times \Delta T$.

\footnotetext{
${ }^{2}$ The GCM datasets were obtained from the IPCC Data Distribution Centre at www.ipcc-data.org. The GCM outputs currently incorporated in ClimGen were used in the IPCC Third Assessment Report (Houghton et al. 2001): HadCM3 A1F1, A2 (ensemble of 3 runs), B1, and B2 (ensemble of 2 runs); ECHAM4 A2 and B2; CSIRO mark 2 A2, B1, and B2; NCAR PCM A2 and B2; and CGCM2 A2 and B2 (each an ensemble of 2 runs)
}

In addition to providing these patterns of mean climate change, ClimGen also combines them with the observed climatology to yield patterns of mean absolute climate, and then combines them with observed time series of deviations from climatology to yield realisations of climate change with realistic year-to-year variability superimposed. The CRU TS 2.1 climatology and monthly time series of Mitchell \& Jones (2005), already interpolated to a grid with resolution $0.5 \times 0.5^{\circ}$, were used for this purpose. The patterns of mean climate change are added to the observations, except in the case of precipitation where various options are available, including the 'ratio method'. This uses the changes in pattern-scaled GCM precipitation expressed as fractional changes from present-day precipitation (e.g. a fractional change of 1.3 would be a $30 \%$ increase) rather than absolute changes (e.g. an increase of $23 \mathrm{~mm}$ per $\mathrm{mo}$ ). The fractional changes are combined with the observed climatology by multiplication rather than addition, as are the year-to-year fluctuations (if the mean precipitation increases by $30 \%$, then the inter-annual variability produced by ClimGen also increases by $30 \%$ ).

Analysis of the GCM simulations indicates that in many regions the inter-annual variability may change independently of the mean precipitation, and in particular in some cases the temporal distribution of precipitation becomes more skewed (i.e. with increased low or high extremes, or both). Here, we apply ClimGEN to modify the observed deviations from climatology, so that the shape of a gamma distribution fitted to the original and modified values changes in the same way as gamma distributions fit to the present and future GCM simulations. The pattern of changes in gamma shape parameter is scaled by the required global-mean temperature change (i.e. the pattern-scaling method is used in a similar way to the scaling of the means of the climate variables). This gamma shape method is described by Goodess et al. (2003). In this study, this third option is selected in order to simulate future changes in precipitation variability as well as mean precipitation.

In the present study, the SCSG receives as input from the SCM the timeseries of annual global mean temperature changes (relative to 1990) from 2001 until (for example) 2100, which are converted internally to a baseline of 1961 to 1990, and the name of the GCM to which the SCM is tuned. It also receives as input the array of years matching the global temperatures from MAGICC. These year dates are used internally by ClimGen only in the final stage of the spatial scenario generation, when historic natural variability is added for the 21st century assuming the 
same sequence and pattern of variability as occurred in the second half of the 20th century (the $50 \mathrm{yr}$ sequence is repeated twice to provide a $100 \mathrm{yr}$ sequence). This allows CIAS to project climate change patterns for any given global greenhouse gas emissions scenario, such as SRES A1B or the stabilization scenarios studied here. The outputs are monthly, seasonal or annual values of 8 climate variables on a $0.5 \times$ $0.5^{\circ}$ grid for the terrestrial land surface. For the present study only monthly precipitation values are used.

\subsection{Measures of drought}

The standardized precipitation index (SPI) (Heim 2002 Lloyd-Hughes \& Saunders, 2002), based on running mean monthly precipitation time series, was calculated for 5 mo droughts (SPI5) and 12 mo droughts (SPI12) for observed monthly precipitation for 1951-2000 and for the monthly precipitation time series provided by the SCSG over the 21st century, considering first the period 2001-2049, and secondly the period 2050-2098. We compared SPI5 and SPI12 values for different time periods and emissions scenarios by: (1) plotting maps of the values in grids covering Europe at a resolution of $0.5 \times 0.5^{\circ}$ latitude and longitude; (2) aggregating these values to study the average picture for individual countries; (3) studying the variation in (1) and (2) with the SCM and SCSG tuned to different GCM climate change patterns.

The 2 periods of 5 and 12 mo were chosen to reflect the 2 characteristic drought types in England and Wales (Hulme \& Barrow 1997, Arnell \& Delaney 2006, Blenkinsop \& Fowler 2007a,b):

(1) A 'short' or 'surface-water' drought, typical length 4 to 6 mo: affects the upland surface reservoirs as occurred in northern England in 1995.

(2) A 'long' or 'water resource' drought, typical length 9 to 15 mo i.e. generally 2 summers with an intervening dry winter: greatest impact occurs on the southeastern region of the British Isles where population growth is the most rapid and groundwater resources are important. The event in 1975/76 is an example of this drought type.

SPI transforms a running-mean precipitation time series from ClimGen into a standardized value via the following formula:

$$
\mathrm{SPI}=\frac{X_{i}-\mu_{i}}{\sigma_{i}}
$$

where $\mu_{i}$ and $\sigma_{i}$ are the sample estimates of the observed precipitation mean and standard deviation, respectively, of the running-mean precipitation in month $i_{i} \mathrm{X}$ can either be the modeled or observed running-mean precipitation value in month $i$. Running means were calculated over 5 or 12 mo periods to obtain SPI5 and SPI12, respectively (Fig. 2).

If the distribution of running-mean precipitation is significantly skewed, then it is common to transform the running-mean values to a more symmetrical, Gaussian-like distribution by fitting a chosen distribution to the data. A gamma distribution is typically used (see Lloyd-Hughes \& Saunders 2002). Even if the underlying monthly precipitation totals are skewed, the central limit theorem indicates that running means will be increasingly close to a Gaussian distribution as the length of the running mean increases. Here we have chosen not to transform the running-mean precipitation via some distribution such as the gamma; Lloyd-Hughes \& Saunders (2002) indicate that this has little affect for running means longer than $9 \mathrm{mo}$, but can influence results in some arid regions for 3 mo running means. Our SPI12 analysis should, therefore, be relatively unaffected, while our SPI5 analysis may yield conservative values in arid regions (i.e. strongly negative SPI5 values may occur less often).

In the present study, we consider that a drought event occurs in a given European grid cell when the SPI5 (or SPI12) value exceeds a particular threshold. The 1951-2000 SPI5 (or SPI12) observational time series is regarded as the reference period. The threshold was defined such that at least one drought event occurs in every grid cell of the European region from 1951-2000. This threshold was then applied to the first (2001-2049) and the second half (2050-2098) of the 21st century for all the regions. The thresholds identified were -1.63 and -1.55 (i.e. standard deviations below the mean) for SPI5 'short' and SPI12 'long' droughts respectively (Figs. 2a-c). A drought was considered to terminate when the SPI5 (12) values of more than 5 (12) consecutive months did not breach the threshold. Thus dry conditions persisting for several years or longer are regarded as a single drought event, resulting in fewer individual events despite extensive drought conditions. Hence analysis of the number of individual drought events and the number of months when the SPI value exceeds our drought threshold can yield different information. Accordingly, we present results for changes in drought frequency as well as the total numbers of months over which drought is experienced. We focus on SPI5 drought frequency only, since results from SPI12 drought frequency may not be as representative as those for SPI5 due to the definition of drought frequency used. The results for SPI12 drought length 

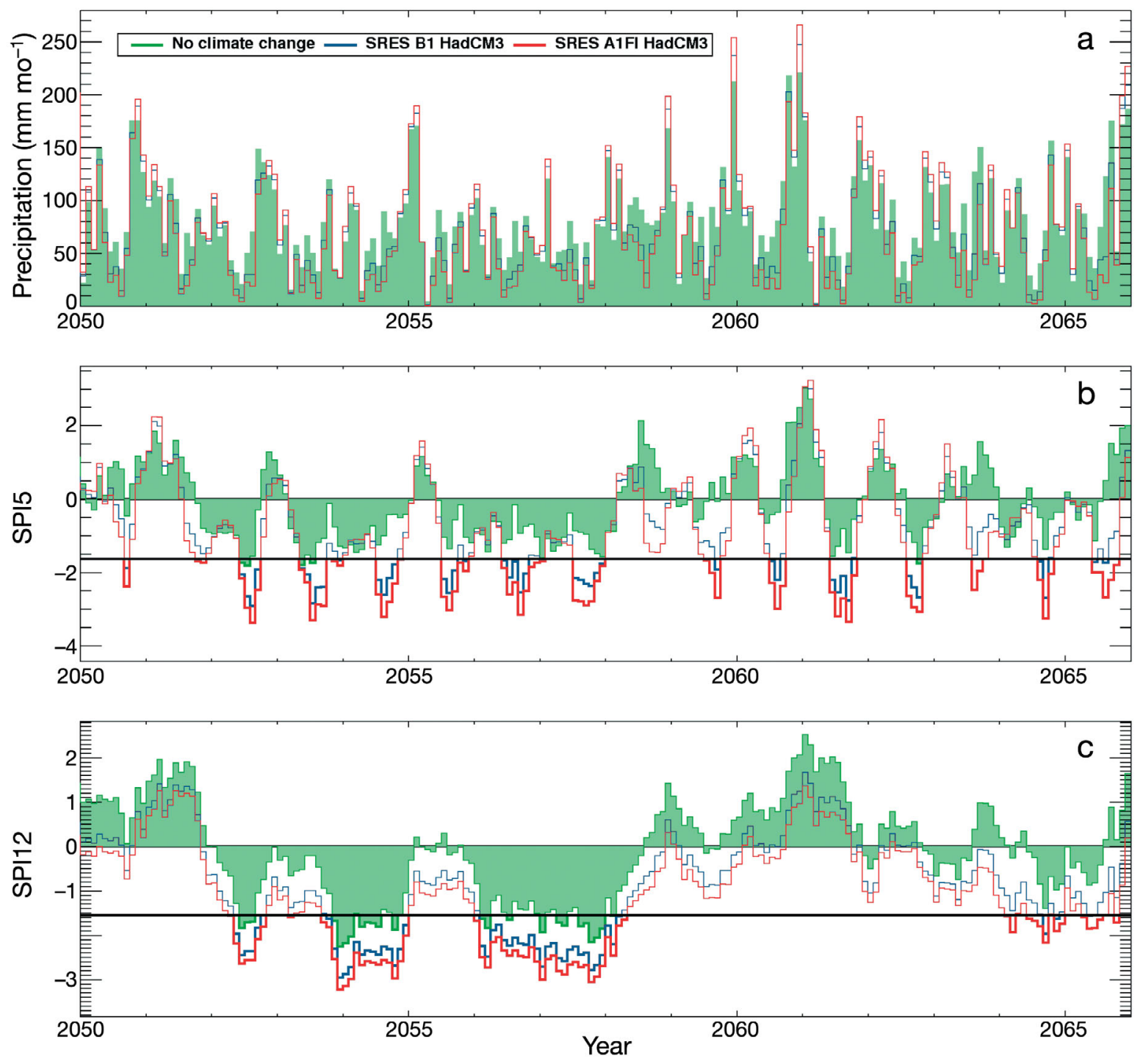

Fig. 2. Standardized precipitation index (SPI) from (a) monthly precipitation totals for (b) SPI5 and (c) SPI12. A sequence of precipitation and SPI under 'no climate change' (green shading) is obtained based on observations from the CRU TS2.1 dataset for the grid box containing Bordeaux, France. Two future scenarios are obtained in ClimGen by modifying the mean and skewness of the precipitation according to patterns of change diagnosed from simulations with HadCM3, scaled according to possible global-mean temperature changes over 2050-2065 (relative to 1961-1990) under SRES scenarios B1 (blue) and A1FI (red). The horizontal black lines in (b) and (c) show the thresholds used to define short and long droughts in the present study, and SPI values that breach this threshold are highlighted with thicker lines

have also been excluded as they are calculated by dividing the total number of drought months by the number of droughts, and the latter can be quite small if droughts combine into few individual events.

Fig. 2 illustrates the calculation of SPI5 and SPI12 time series from monthly precipitation for three $16 \mathrm{yr}$ sequences of precipitation in SW France, one based on observations and 2 from future scenarios generated by ClimGen. The green shading illustrates the sequence based on precipitation observations (note that the years indicated on the $x$-axis are the years of the future scenarios, not the years from which the observed precipitation was taken - see previous section). In this particular sequence, precipitation is relatively low from 2051-2056, and is higher thereafter. This results in mostly negative SPI values from 20522057, though SPI5 only occasionally breaches the threshold used to define drought in this paper. SPI12, however, breaches the threshold 3 times during this period, which would be counted as 3 droughts. Under the 2 future scenarios illustrated in Fig. 2, there is an increase in the seasonality of precipitation, with summers becoming still drier and an increase in precipitation during winter months. This 
enhanced seasonality results in short droughts (SPI5 $<-1.63$ ) occurring nearly every summer, while some winters still have SPI5 values similar to those obtained from the observations. Though the negative SPI5 values become even more extreme under the A1FI scenario compared with the B1 scenario, there is little difference between the scenarios in the number of events or the total number of months that exceed the particular threshold used here. A threshold of -2.5 would yield greater differences between B1 and A1FI. The reduction in April to October precipitation under these HadCM3 scenarios exceeds the increase from November to February so that the annual total is reduced; this is clear in SPI12, where the scenarios are consistently lower than the values obtained from the observed precipitation. The gap between the first 2 long droughts (2052 and 2054) is now less than $12 \mathrm{mo}$, and so we count these as a single event. The SPI12 values lie above the threshold for all months from February 2055 to January 2056, even under A1FI, and thus the subsequent drought event in 2056-2057 is counted as a separate event from the 2052-2054 event.

The total number of months under drought is defined by summing all the months whose SPI values are below the threshold during the $49 \mathrm{yr}$ period.

\section{RESULTS}

Over the second half of the 21st century, drought conditions intensify in southern Europe as climate changes according to the HadCM3 patterns of precipitation change (Figs. 3 to 5, Fig. S11 in the Supplement www.int-res.com/articles/suppl/c051p105_supp. pdf). The most affected areas surround the Mediterranean and the Black Sea, but drying also occurs in northwestern Europe, including the south of England. There are signs of wetting in the higher latitudes, namely in Scandinavia and parts of northern Russia.

Pronounced increases in all 4 measures of drought are projected for all 5 SRES scenarios. These trends express themselves most strongly through changes in the number of months under drought which last at least 1 year (Fig. 3) or at least 5 mo (Fig. S11) and through increases in drought frequency (Fig. 4), which could be enormous across large areas of Europe by 2100. The frequency of droughts of at least 5 mo duration is projected to rise from around 10 events per $49 \mathrm{yr}$ period, to over 30 in southern and central Europe in the more extreme A1FI, A2 and A1B scenarios
(Fig. 4). The number of months over a $49 \mathrm{yr}$ period during which droughts in excess of 12 mo duration are being experienced is projected to increase from 50 to over 300 (which means that year-long drought is projected to occur for more than $50 \%$ of the time) in the worst affected parts of southern Europe if no mitigation of emissions occurs. Whilst increases are also seen in the average drought length for droughts of 5 to 12 mo duration, this indicator showed less pronounced trends suggesting that climate change tends to increase drought frequency rather than drought length, although the 12 mo cut-off in the indicator may produce a misleading impression.

Fig. 6 and Figs. S12 \& S13 show outcomes averaged over 4 selected countries for the SRES scenarios compared to current climate, for 3 different GCM patterns. Southern European countries such Spain and Romania see strong drying by the second half of the 21st century, whilst northern European countries such as Finland show wetting. This is further illustrated in Figs. 7 to 9 and Fig. S14. Comparison of Figs. $7 \& 8$ with Fig. 9 and Fig. S16 show that CSIRO2 produces a significantly more easterly pattern of drying, also confirmed in Fig. 6 and Figs. S12 \& S13, with little drying in Spain and extreme drying in Romania.

ECHAM4 suggests largest increases in drought will be focused in southwestern Europe (e.g. Spain), whilst CSIRO2 projects that the worst affected area will be in southeastern Europe, especially surrounding the Black Sea (as shown for the high emissions scenario A1FI in Fig. 9). HadCM3 projects increases in drought around both the Mediterranean and the Black Sea (Fig. 7).

SRES scenarios with higher emissions show more pronounced effects in the second half of the 21st century. Over the first half of the century (not shown), significant increases in drought frequency and the number of months affected by drought are also projected. However, spatial patterns and magnitude of the change in drought frequency across Europe reveal little difference between the various SRES emissions scenarios, since the time lags in the earth system mean that the full response to emissions for 2000-2050 has yet to be realised. Projected global annual mean temperature change for various SRES emissions scenarios is very similar up until 2030, e.g. $1.2^{\circ} \mathrm{C}$ above 1990 levels for HadCM3 (Figs. S5 \& S6). Although divergence in temperature rise for both sets of scenarios begins in the 2030s, the differences are small till 2050.

Mitigation has a relatively small effect on the outcomes in the first half, but a dramatic effect in the 


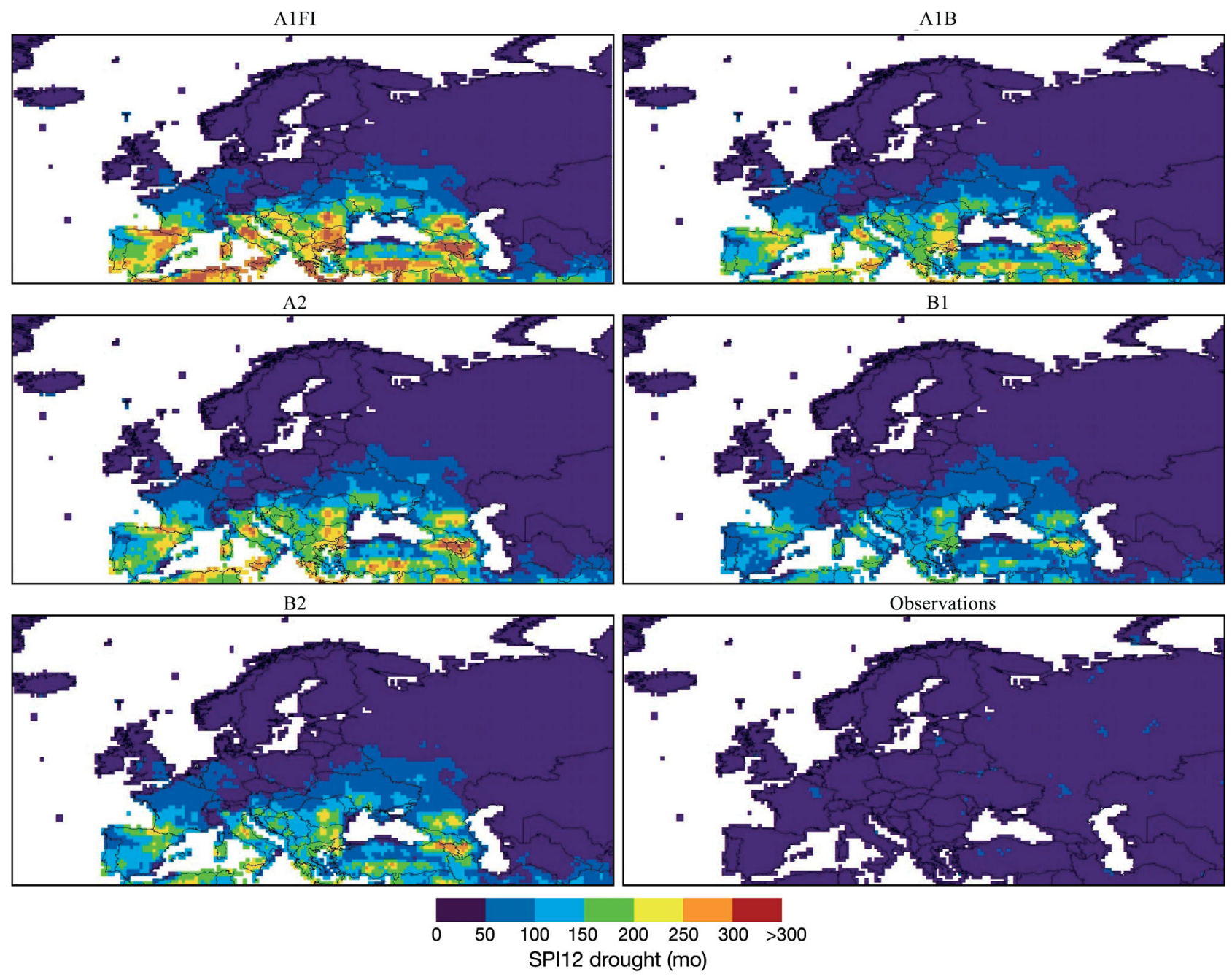

Fig. 3. Total number of months under SPI12 drought in 2050-2098, simulated by CIAS tuned to HadCM3, compared with current observations

second half of the 21st century. Figs. 7 to 9 show projections of drought indicators for 2050-2098 in the A1FI SRES scenario and in various stabilization scenarios. Large reductions in southern European drought are seen upon stabilizing greenhouse gas concentrations, with more effective reductions for more stringent stabilization scenarios. These reductions are further quantified in Figs. 10-12 and Fig. S18 which show that the greatest benefits occur in Spain, Bulgaria, Italy and Greece (HadCM3 based simulation), Spain, France and Italy (ECHAM4based simulation, Figs. S15 \& S19) or Ukraine, Bulgaria, Turkey and other countries surrounding the Black Sea (CSIRO2 simulation, Figs. S16 \& S17). In some areas, over 200 mo of long drought might be avoided through moving from an A1FI baseline scenario and a 400 ppm mitigation scenario; or similarly over 300 mo of short drought, or 20 short drought events, might correspondingly be avoided. However, even under these stringent mitigation scenarios, some increases in drought still occur in these cases relative to 1951-2000. Drought length, on the other hand, changed relatively little under stabilization scenarios (not shown).

Figs. 9 \& 12 (and also Figs. S15 to S17, S19 to S21) show that the considerable reductions in the number of months affected by year-long droughts and drought frequency simulated by HadCM3 are robust to the use of different GCM choices for climate projection and spatial patterns (specifically CSIRO2 and ECHAM4). Further, the reductions are larger than the range of variation in drought projection for given emissions scenarios simulated by a range a GCM patterns.

Fig. 6 and Figs. S12 \& S13 show the countryaveraged results for the UK, Finland, Spain and Ro- 

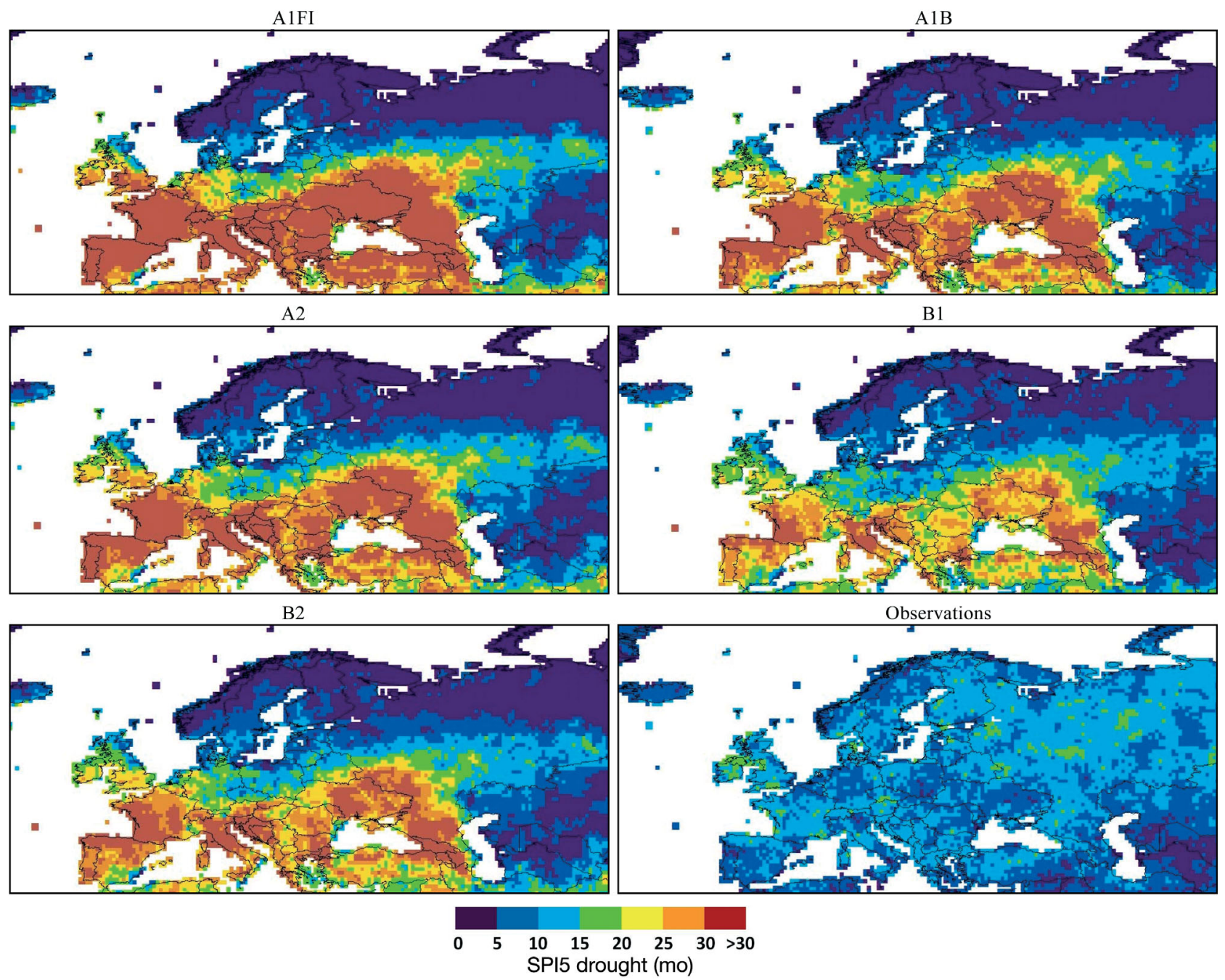

Fig. 4. Absolute frequency of SPI5 drought events in 2050-2098, simulated by CIAS tuned to HadCM3, compared with current observations

mania. Clear reductions in the increases in drought indicators are evident for Spain and Romania, whilst reductions in wetting are apparent for Finland. Comparing baseline scenarios A1FI and A1B against the stringent mitigation scenarios (400 and $450 \mathrm{ppm}$ ), over 2050-2098, some 100 to 200 mo of extended (year-long) drought across Spain might thus be prevented, and, similarily, some 35 to 105 months of extended (year-long) drought might be prevented in Romania (HadCM3 and ECHAM4), with the largest benefits corresponding to a comparison of the A1FI scenario with the $400 \mathrm{ppm}$ scenario. Using CSIRO2, whilst Spain is unaffected, instead 40 to 150 mo of long drought might be prevented in Romania.

Figs. S5 \& S6 show how the emissions scenarios diverge over the 21st century in terms of globalmean temperature outcomes at this period, using the
HadCM3 model: with a 400 ppm stabilization scenario resulting in a global temperature increase of $0.9^{\circ} \mathrm{C}$, whilst an SRES A1FI scenario results in one of $5^{\circ} \mathrm{C}$ relative to 1990 .

The simulations also show a wide range of possible drought climates in Europe during the 21st century. The range of values for the number of months under drought of at least 12 mo duration, or between 5 and 12 mo duration, that an adaptation planner might need to consider in the first and second half of the century, can be deduced. For example, Figs. $7 \& 9$ and Fig. S15 illustrate the range of possible simulated outcomes for SPI12. These span the full range of emission scenarios considered here and a sample of GCM patterns. Under the most stringent scenario there are still significant increases in drought, as defined here, compared to current observations. 

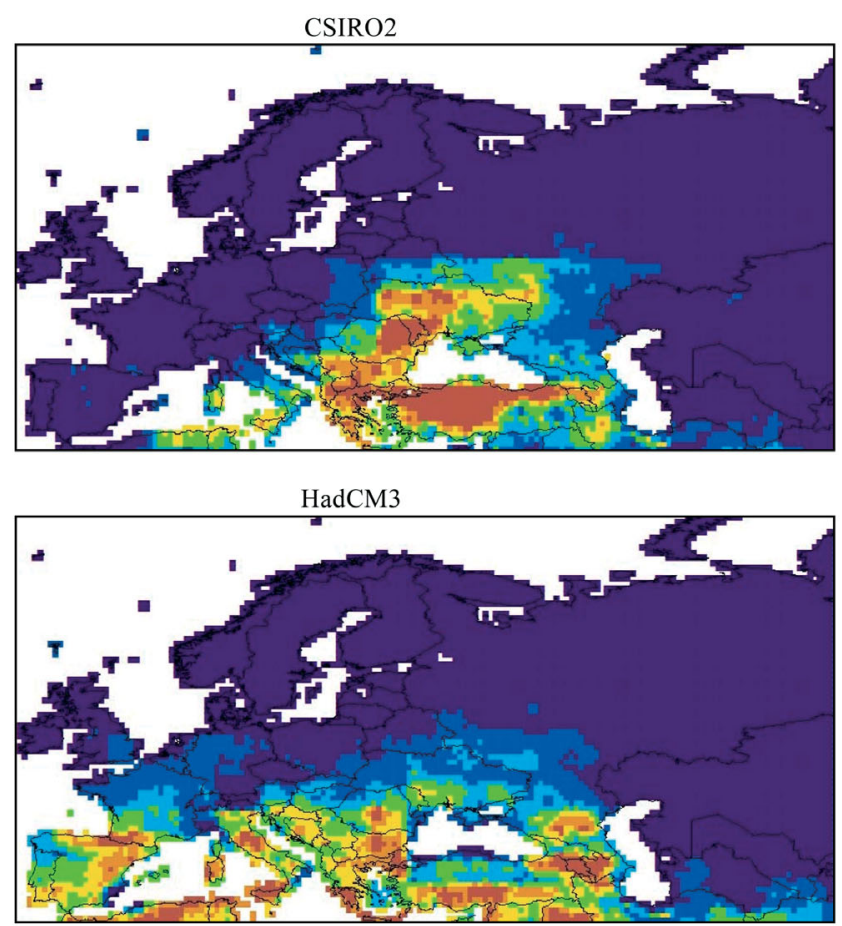

\section{DISCUSSION}

The present study used the CIAS framework to produce projections of climate-change induced changes in drought length and frequency that are potentially of use to regional adaptation planners and global mitigation planners ${ }^{3}$. The study has (1) produced estimates of projected increases in drought not only in the SRES reference scenarios, but also in scenarios in which climate policy is applied to stabilize $\mathrm{CO}_{2}$ concentrations at 3 different levels between 400 and 500 ppm by 2100, (2) mapped the projected benefits of this mitigation, in terms of avoided increases in drought, across Europe using various indicators and (3) taken into account a range of 3 GCM climate change patterns.

There is a general pattern of wetting in northern Europe and severe drying in south and southeastern Europe, separated by a boundary whose location varies across GCM simulations; thus, in some midlatitude areas of Europe there are uncertainties in the direction of change. For example, CSIRO2 indicates wetting across the southern part of the British Isles

\footnotetext{
${ }^{3}$ Adaptation planners may identify 'no regret' strategies that could be pursued, such as reducing overall water demand across the continent. Such strategies are independent of the uncertainties in the magnitude of increased drought (EEA 2007)
}
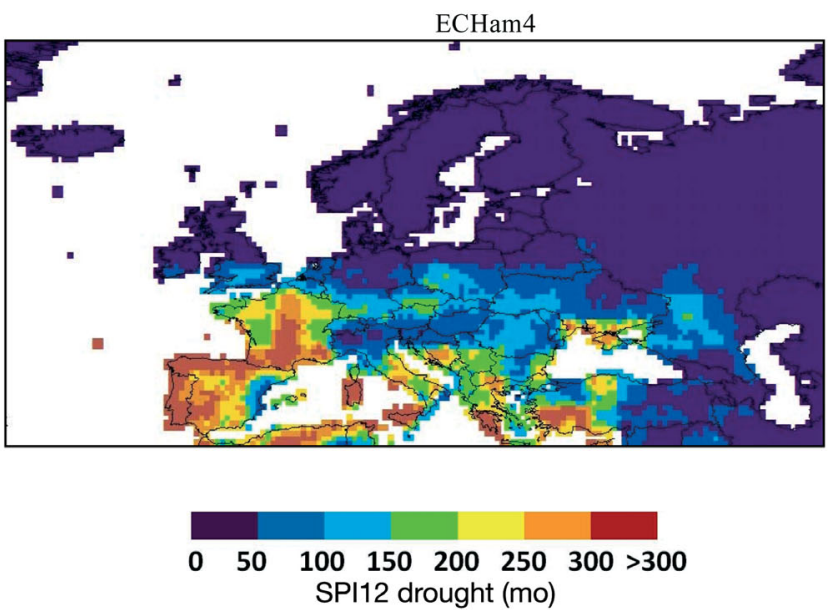

Fig. 5. Total number of months under SPI12 drought in 20502098, simulated for the SRES A1F1 scenario, simulated by CIAS tuned to various GCMs

whilst ECHAM4 and HadCM3 indicate drying. However, for the majority of Europe, the trends are consistent for either drying or wetting. Whilst stringent mitigation avoids most of the very large drought increases which would otherwise occur, in some countries - such as Spain and Romania - our results indicate that some significant increases in drought may be inevitable even under strongest mitigation scenarios.

Whilst stabilization of $\mathrm{CO}_{2}$ concentrations at 550 or $500 \mathrm{ppm}$ does reduce the drought impacts, stringent stabilization at 450 to $400 \mathrm{ppm}$ is required to avoid the greater part of the impacts.

The model simulations are most useful for gaining insights into the magnitudes of climatological drought that might be experienced across wide regions. Detailed study of individual grid cells would be not be appropriate since individual river catchments and detailed topography are not resolved by the GCMs from which the patterns of precipitation change were diagnosed.

Enhanced seasonality of precipitation (i.e. reduced mean summer precipitation and increased for winter) has also been projected for the 21st century across Europe (Hulme et al. 2002, Burke et al. 2006, Blenkinsop \& Fowler 2007a,b). More severe summer droughts may be associated with reduced precipitation during the preceding winter, particularly in catchments where groundwater storage is important, 


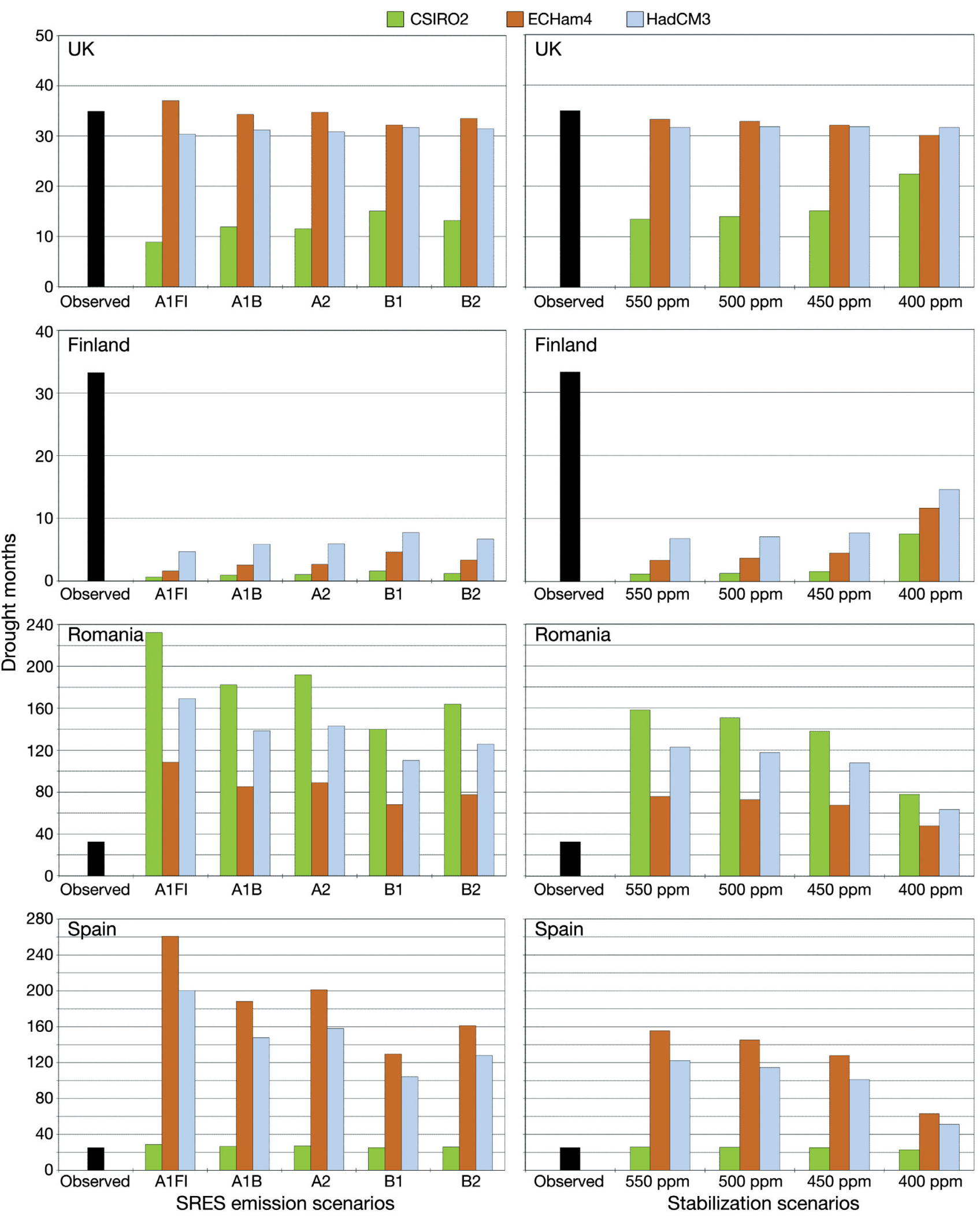

Fig. 6. Variation in total number of months under SPI12 drought in 2050-2098 under SRES scenarios and in $\mathrm{CO}_{2}$ stabilization scenarios, compared to current observations, expressed as averages over 4 European countries, showing the effect of tuning the climate model to emulate the behaviour of 3 different global circulation models 


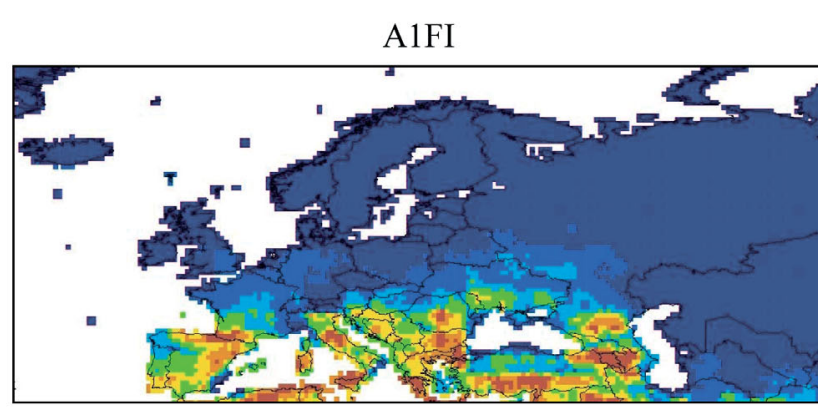

$550 \mathrm{ppm}$

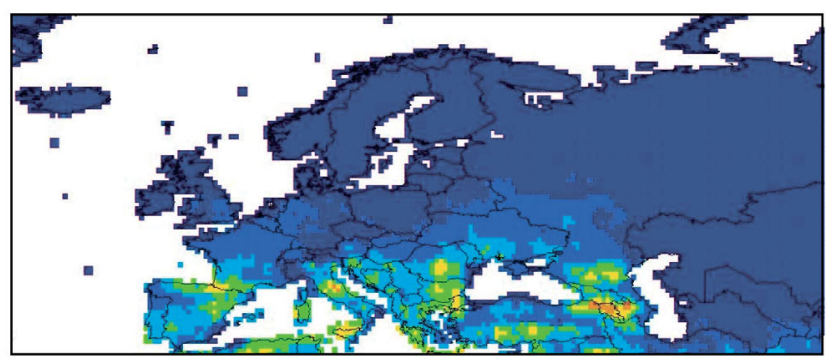

$450 \mathrm{ppm}$

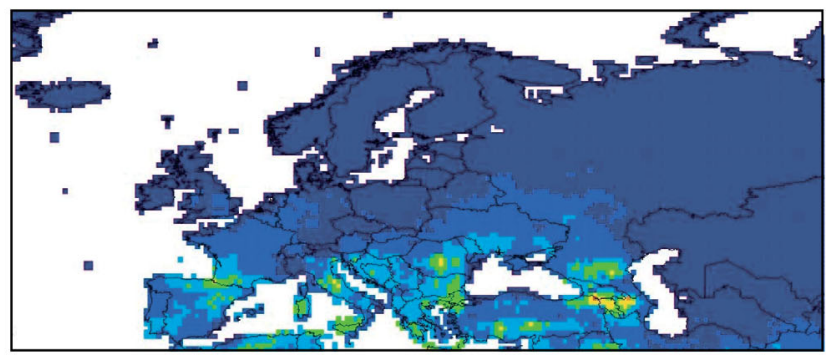

$0 \quad 50100150200250300>300$

SPI12 drought (mo)

Fig. 7. Total number of months under SPI12 drought in 2050-2098, simulated by CIAS tuned to HadCM3, for the A1FI SRES scenario and 4 stabilization scenarios in which $\mathrm{CO}_{2}$ is stabilized at 550,500 and 450 ppm respectively (see Fig. S1-S9 in the Supplement, www.int-res.com/articles/suppl/c051p105_supp.pdf), and a further extreme scenario stabilizing at 400 ppm $\mathrm{CO}_{2}$

whereas summer precipitation is a more crucial factor in catchments with limited storage capacity (Hisdal et al. 2001). Further investigation of the effect of seasonal changes in precipitation is needed to aid interpretation of longer-duration droughts, which is dependent on the balance between rainfall deficit in the summer and enhanced winter precipitation.

Our findings are consistent with a number of other studies of changing extreme precipitation. For example, Fowler et al. (2007) use an alternative approach based on 6 RCM integrations driven by 2 GCMs (ECHAM4 and HadCM3) and found that all model combinations project increases in the return values (the highest value occurring on average once in a defined period of time) of extreme precipitation for most of Europe. It should be noted that this study is based on a direct analysis of a daily time series produced by RCMs, rather than a monthly time series, but the projections are still consistent with the find- ings of the present study. Frei et al.'s (2006) analysis of the implications of the SRES A2 scenario also projected decreases in return periods (the return period of an extreme precipitation event which has a particular magnitude is the average time between extreme precipitation events of that magnitude) for extreme precipitation events. More recently, Sheffield \& Wood (2008) projected future global drought in the 21st century using a suite of 8 GCMs for the A2, A1B and B2 emission scenarios. A global decrease in soil moisture was found with regional hotspots in a number of areas, with the area first affected projected to be the Mediterranean. Similarly, Sillmann \& Roeckner (2008) projected significant increases in consecutive dry days in Mediterranean countries for an A1B scenario in the 2080s using post-processed output from the ECHAM-4 GCM. Planton et al. (2009) examined global outputs of 6 of the GCMs used in IPCC AR4 and noted that the change in the maxi- 
A1FI

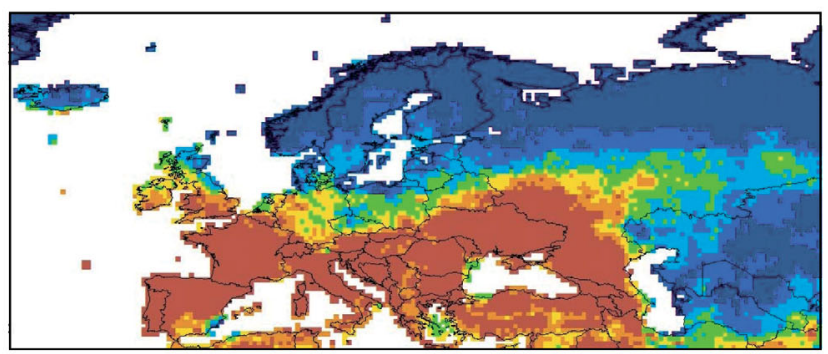

$550 \mathrm{ppm}$

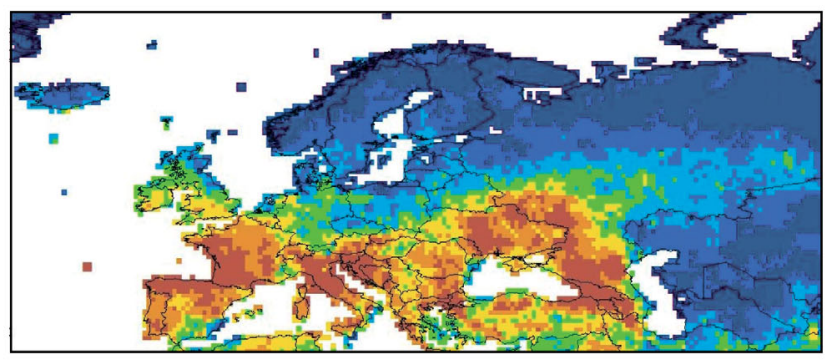

$450 \mathrm{ppm}$

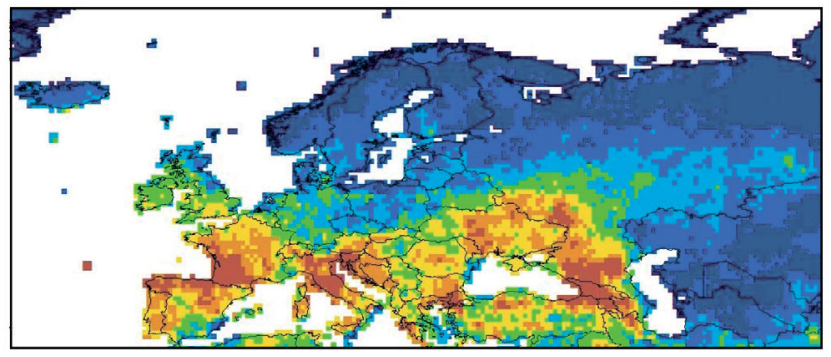

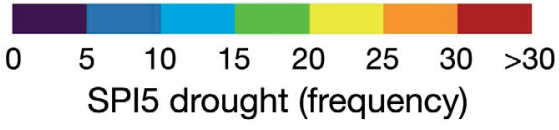

$500 \mathrm{ppm}$

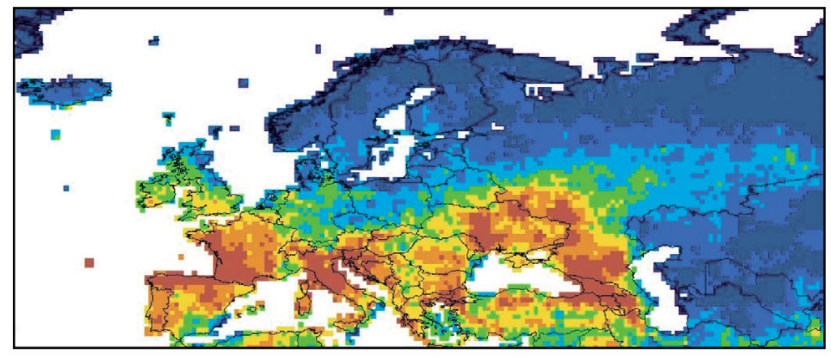

$400 \mathrm{ppm}$

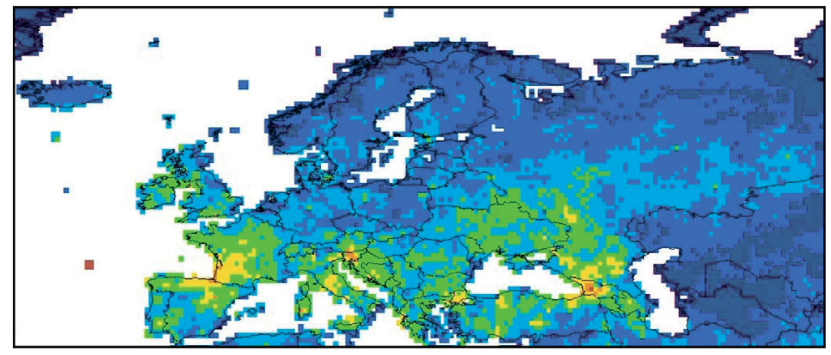

Fig. 8. Absolute frequency of SPI5 drought events in 2050-2098, simulated by CIAS tuned to HadCM3 under A1FI and 4 stabilization scenarios in which $\mathrm{CO}_{2}$ is stabilized at 550, 500 and $450 \mathrm{ppm}$ respectively (see Fig. S1-S9 in the Supplement, www.

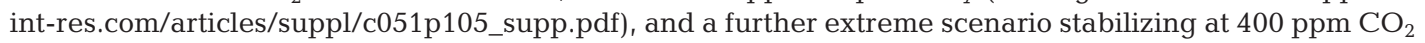

mum number of consecutive dry days is fairly consistent between models for the Mediterranean region. Costa \& Soares (2009) have identified pronounced observed trends in indices of aridity in southern Portugal for 1955-1999, showing that the area is vulnerable to drought and desertification. Gao \& Giorgi (2008) used a high-resolution regional climate modelling approach to project A2 and B2 SRES scenarios to 2100, and identified pronounced increases in 3 different aridity indicators in the Mediterranean region, in particular identifying a northward extension of the arid lands. Such a northward extension is also apparent in Figs. 4, 5 \& 10 to 12, Figs. S19 to S21. Hence a critical risk area for drought in southern and southeastern Europe has been identified by a wide range of independent studies.

The largest source of uncertainty in our projections is related to the ability of the GCMs to simulate realistic changes in the patterns of precipitation across
Europe, together with the representation of these changes as quasi-linear functions of global-mean temperature change for pattern-scaling within ClimGen. Evaluating GCM simulations of presentday climate (e.g. Gleckler et al. 2008) is one indication of model performance, though of course it is no guarantee that the response to forcings will be simulated well and it is difficult to convert a measure of similarity into some quantitative indication of how much confidence can be placed in the future projections. Large-scale evaluations such as that reported by Gleckler et al. (2008) are particularly useful for indicating relative performance between GCMs, or for documenting improvements over time, or for identifying relative performance between variables. In the extra-tropics, precipitation patterns and seasonal variations are typically simulated more realistically than cloud cover, but notably less well than temperatures and atmospheric circulation. The 
A1FI

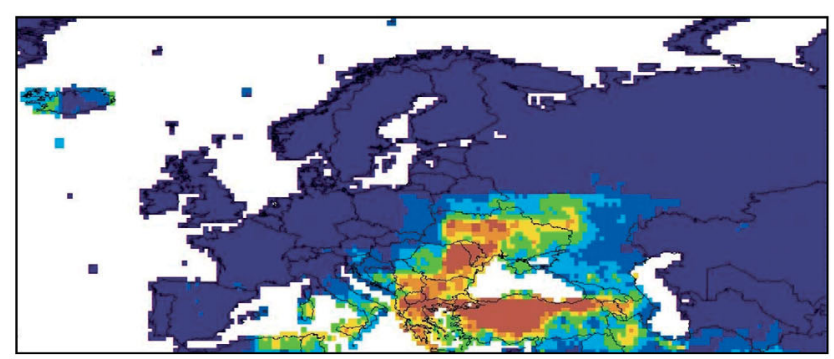

$550 \mathrm{ppm}$

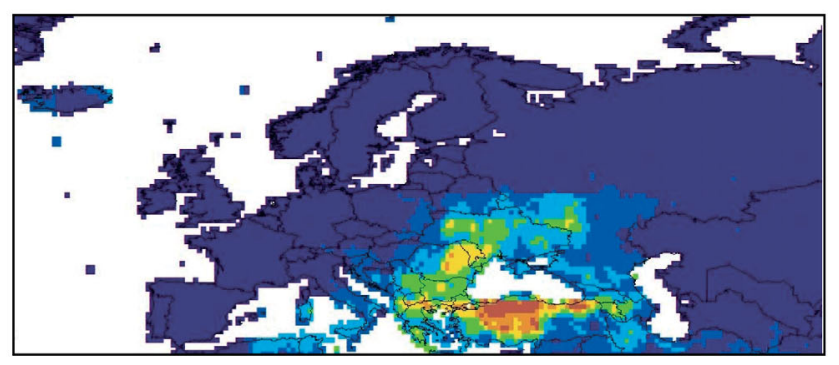

$450 \mathrm{ppm}$

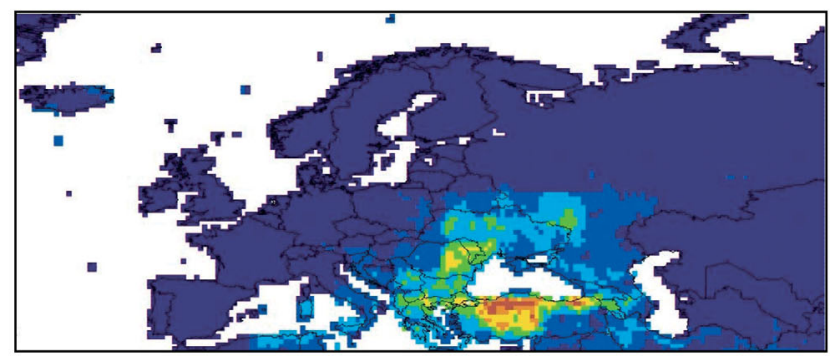

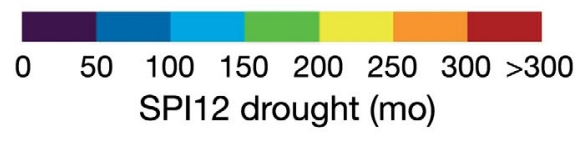

$500 \mathrm{ppm}$

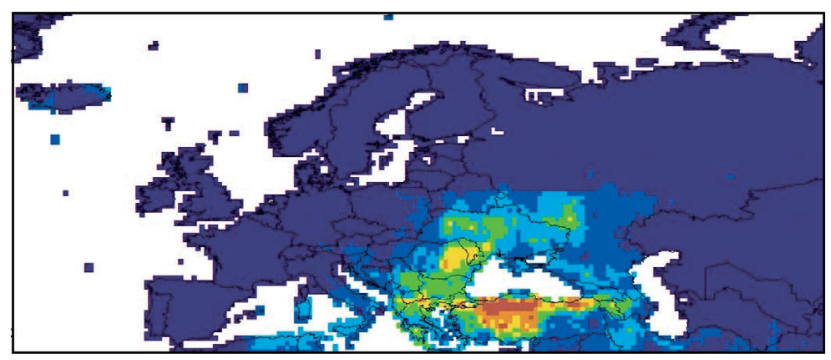

$400 \mathrm{ppm}$

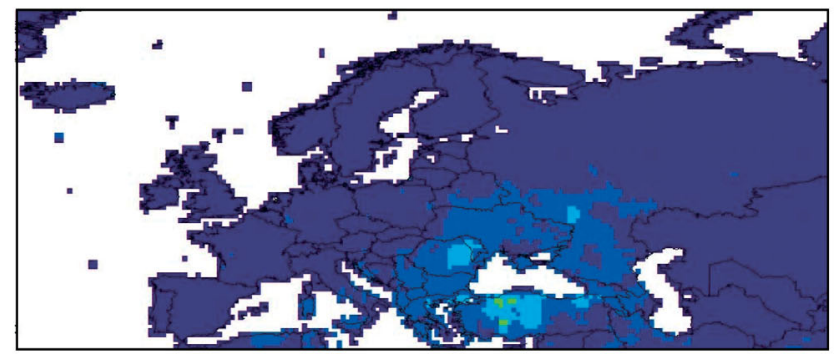

Fig. 9. As in Fig. 7 but using CIAS tuned to CSIRO2

large-scale evaluation of Burke et al. (2006) focussed on patterns of drought and their link to sea surface temperatures; the dominant patterns of drought variability linked to the El Niño-Southern Oscillation, were similar in the observations and in the HadCM3 model simulations, including the reduced drought over southern Europe (their Fig. 1).

Specific evaluations over Europe have focused on small regions (e.g. for Greece by Tolika et al. 2006, for Iberia by Trigo \& Palutikof 2001) or considered regional climate models with higher resolution (e.g. Blenkinsop \& Fowler 2007b). Gross spatial and seasonal structures of precipitation simulated by the models tend to be similar to those observed, but details such as the timing or amplitude of the seasonal cycle, the strength of the north-south gradient (Raisanen 1994), and the influence of complex topography and coastlines, tend to be poorly simulated in models with similar resolution to those used here.

Planners need also to understand the limitations of the SPI drought index. It is simple, requiring only a monthly precipitation time series, and is readily understood by non-scientists, particularly as it has been standardized and is widely used; and its variable timescale allows separate study of 'short' and 'long' drought events (Hayes et al.1999, LloydHughes \& Saunders 2002). In particular, SPI is a measure of climatological drought that does not take into account other features of a changed climate which could impact on drought occurrence. Temperature changes and their effect on evapotranspiration rates, along with humidity, wind and vegetation characteristics that control evaporative losses (Hisdal et al. 2001), are implicitly assumed to be constant. Some studies suggest that increases in evapotranspiration are likely, given the projected changes in temperature (Goodess et al. 2003, Blenkinsop \& Fowler $2007 \mathrm{a}, \mathrm{b})$, which implies that the increases in drought frequency and length projected here are underestimates. However, observations in the UK have suggested that evapotranspiration may actually decrease during drought periods (Marsh 2001) because 

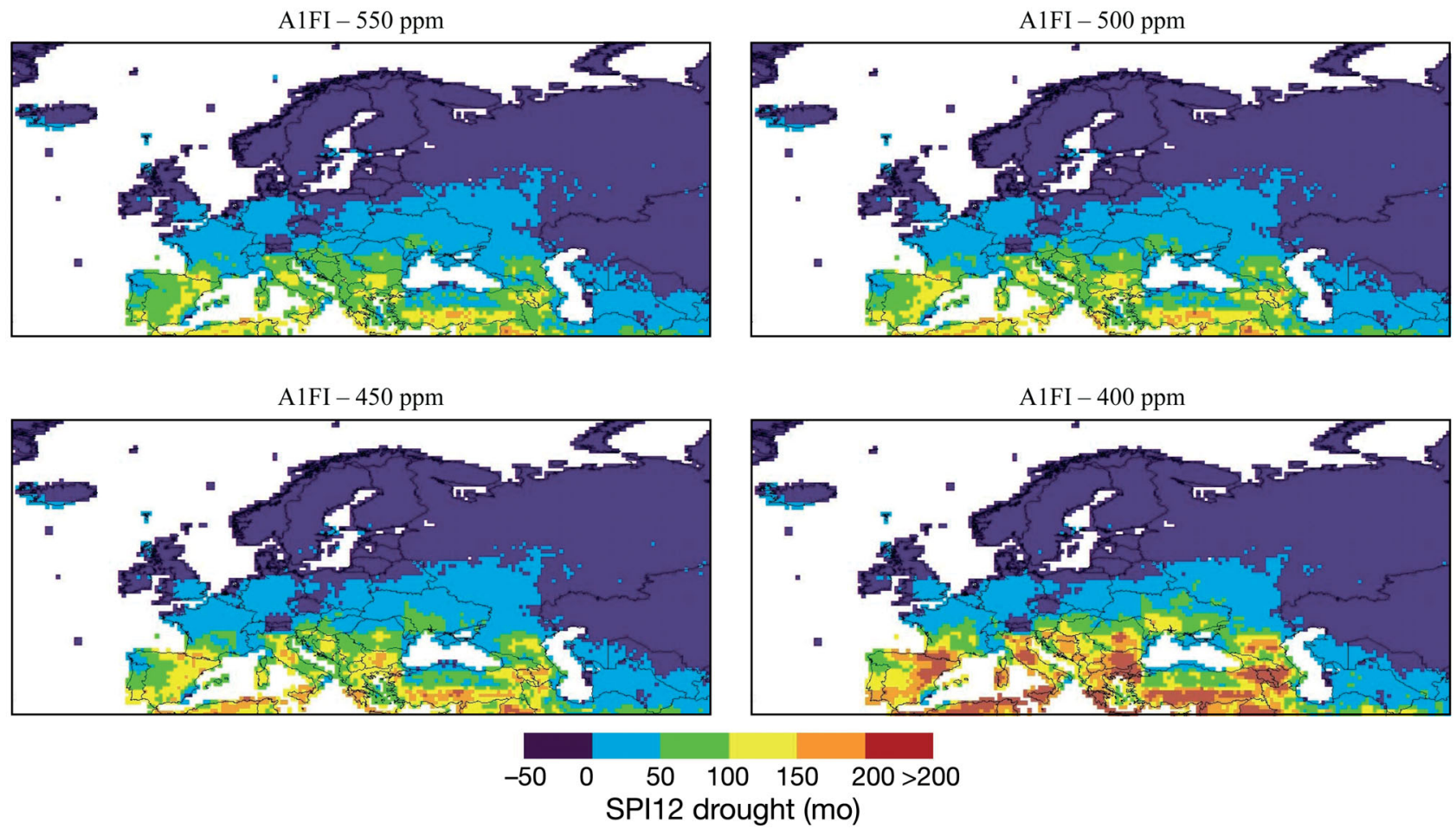

Fig. 10. Reduction in number of months under SPI12 drought in 2050-2098, simulated by CIAS tuned to HadCM3, between the A1FI SRES scenario and 4 stabilization scenarios
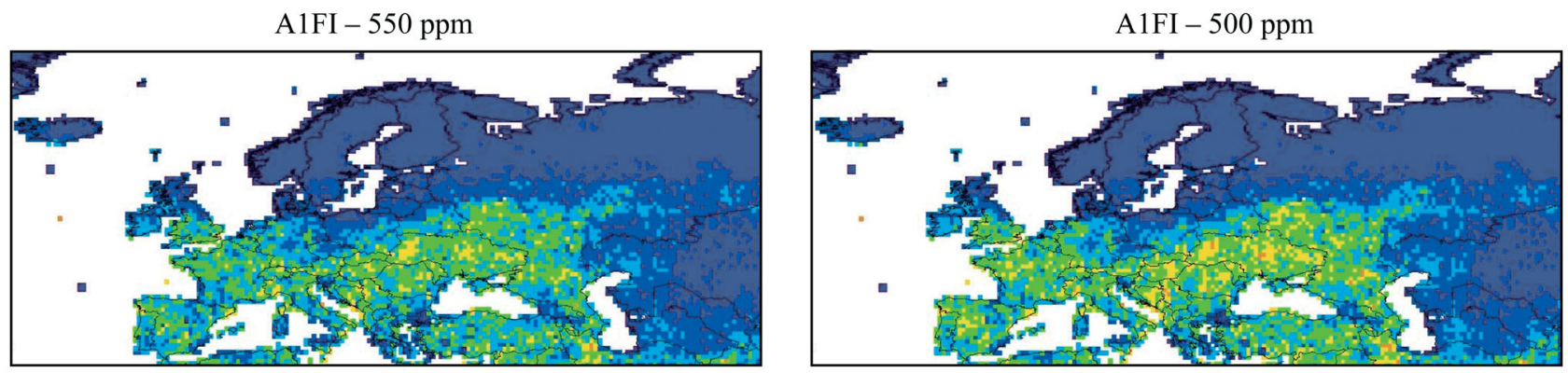

\section{A1FI - 450 ppm}
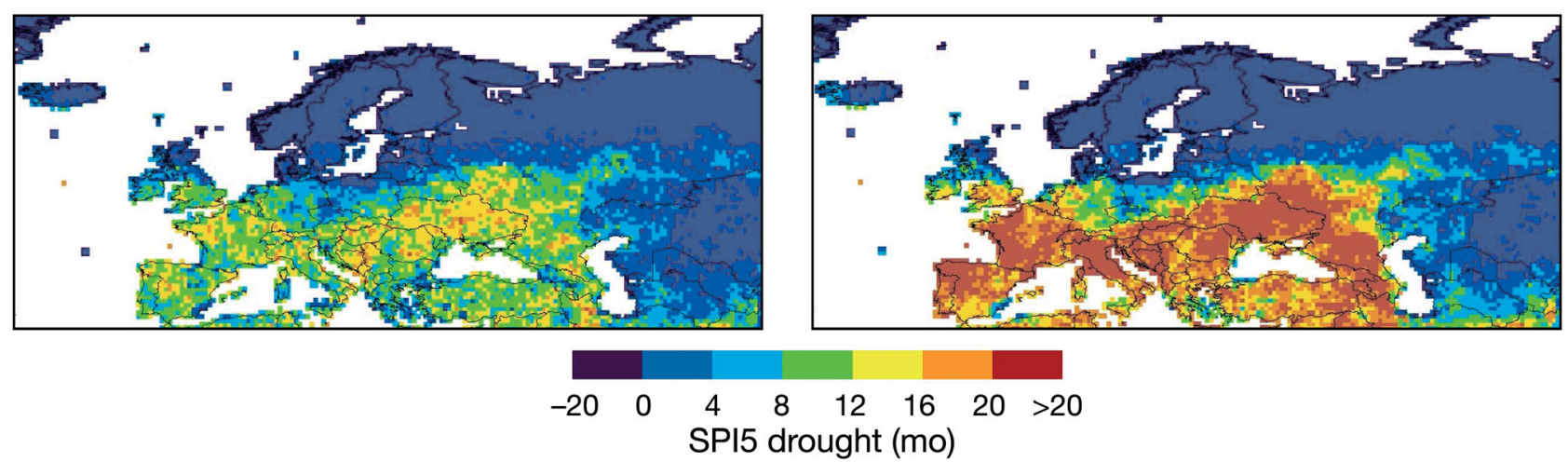

Fig. 11. Reduction in frequency of SPI5 drought events in 2050-2098, simulated by CIAS tuned to HadCM3 between A1FI and 4 stabilization scenarios 

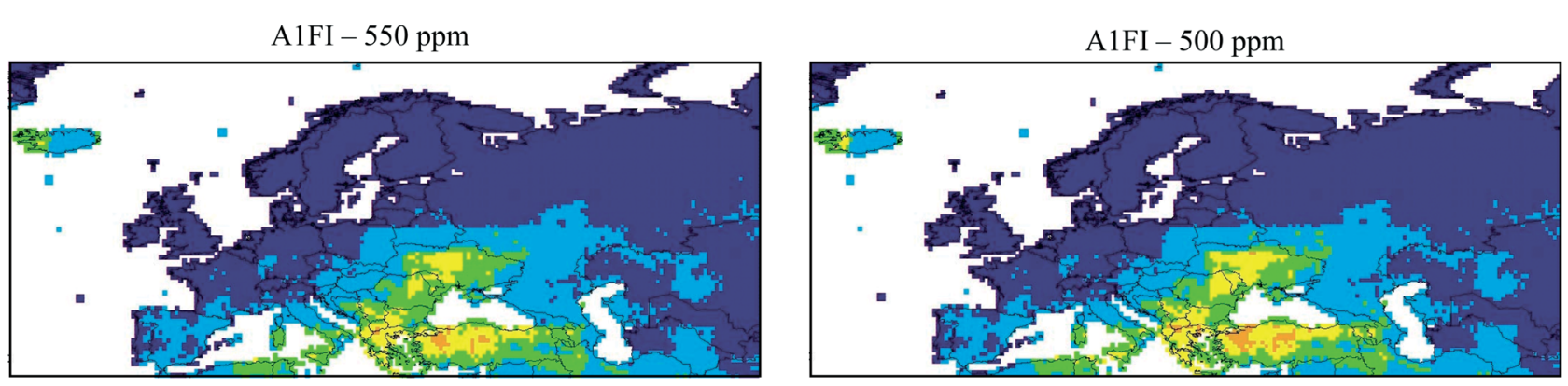

A1FI - 450 ppm

A1FI - 400 ppm

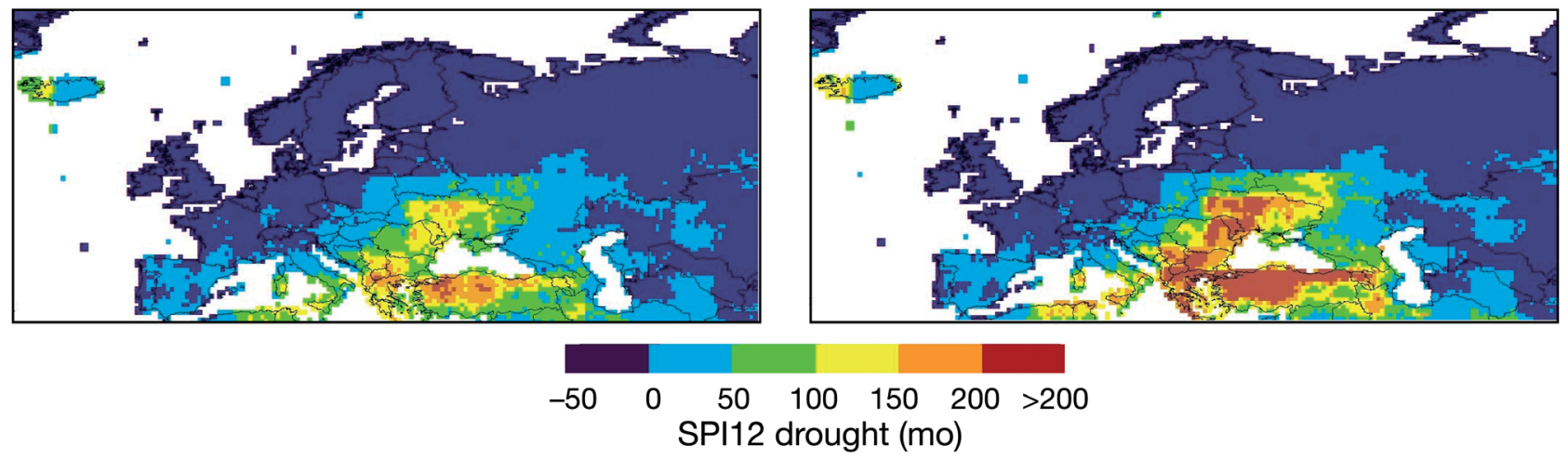

Fig. 12. As in Fig. 10 but using CIAS tuned to CSIRO2

losses may be limited by soil moisture deficits. Furthermore, Gedney et al. (2006) found that observations of runoff across 5 continents over the 20th century were consistent with an inhibition of water loss from stomata as atmospheric $\mathrm{CO}_{2}$ concentrations rise, which would tend to reduce evapotranspiration (Betts et al. 1997). Either of these situations would have implications for water resources, since increased (reduced) evapotranspiration would tend to reduce (increase) runoff. Such processes can be simulated through use of a hydrological model. This is currently under further study using the Community Integrated Assessment System (Warren et al. 2008).

Our use of the SPI was based on the control period of 1951-2000. Whilst this period may not necessarily be characteristic of long-term 'mean' climate, the lack of a consistent data set across Europe going back $100 \mathrm{yr}$ makes this difficult to assess. Hence, we believe that our approach is appropriate, although it is thought that in the UK the period 1951-2000 may have been relatively benign in terms of drought occurrence (Marsh et al. 2007). The SPI also does not consider the potential changes in the hydro-meteorological system resulting from changes in the (mainly sub-monthly) temporal distribution of precipitation events (Blenkinsop \& Fowler 2007a,b). For example, under climate change, climate variability increases and rain may tend to be more concen- trated in heavy precipitation events. In areas where this occurs, or where precipitation merely increases, flow of surface water may be enhanced at the expense of the recharging of groundwater aquifers.

The SPI is useful for highlighting changes in the occurrence of climatological drought. A particular advantage of choosing the spi indicator to analyse drought (as opposed to other indicators) is that all regions are treated equally regardless of the local climatology. However, the impacts of a 12 mo drought in Spain will be much different from that of one in Finland. Therefore, at a regional or local scale a more complex index may be more appropriate for use as a proxy for other types of drought (Blenkinsop \& Fowler 2007b) depending on the local characteristics. The approach used in the present study provides a simple method to assess the future changes in drought events across a large continent.

Changes in land use (e.g. agricultural intensification and afforestation), as well as socio-economic factors that affect water demand (e.g. population growth and economic development) will also have an effect on drought events (Blenkinsop \& Fowler 2007b). These are beyond the scope of this study, but Lehner et al. (2006) combine climatic change with demographic, socioeconomic and technological trends in an integrated water assessment model WATERGAP, which couples climate-change induced precipitation 
changes to a hydrological model and a human water use model, to produce projections of potential future flood and drought risks in Europe, using river flow discharge as a drought indicator. Taking into account the effects of altered human water use, they identify a critical risk area for drought in southern and southeastern Europe, which is also identified as a risk area by the present study. Hence the identification of areas at risk is robust to very significant differences in methodology. Lehner et al. (2006) developed pseudo-daily precipitation time series from monthly precipitation time series and also took into account effects of changes in temperature and cloud cover, but considered only 2 GCM patterns and a single future socioeconomic scenario similar to SRES A1B. Lehner et al. also ignored projected changes in natural variability which are included here via the gamma shape parameter option described in Section 2.3, which was selected in the use of ClimGen. In both studies the effects of seasonality are ignored, an aspect which is potentially of profound importance to planners. Lehner et al. (2006) reported that HadCM3 simulates a 1 mo advancement in snowmelt-associated discharge. Direct comparison of results with Lehner et al. (2006) is not feasible since although they also study a scenario driven by HadCM3 in the late 21st century, additional factors of hydrology and water use are included. Further, Lehner et al. (2006) consider the future rate of return of the current $100 \mathrm{yr}$ drought in various countries, which is estimated to shrink to 40 years, or in extreme cases 10 years, over Portugal, the Mediterranean countries, Hungary, Bulgaria, Romania, Moldova, Ukraine, and S Russia. Weiss et al. (2007) similarly estimate 10-fold reductions in return rates of the $100 \mathrm{yr}$ drought in the 2070s under an A2 scenario.

Our drought frequency results are not simple to interpret because drought events that last for several years or longer would be regarded as a single event. Hence, in some cases an apparent reduction in drought frequency could be masking a trend towards a series of fewer but much longer droughts. Hence it is important to view these projections together with projections of changes in drought length, or together with projections of the total number of months under drought in a 49 yr period.

Ideally, projections across the 3 GCMs used in the study could be combined to form a probabilistic projection. This was not attempted since a sample of 3 models is not sufficient to warrant such an analysis. We are currently extending the range of GCM patterns utilized in our modelling system, so that multimodel emsembles may be constructed. Probability distributions could then be produced through application of techniques such as that described by Tebaldi et al. (2006) in which GCMs are weighted according to their ability to predict current climate in the region of interest.

Our future work will provide a more detailed analysis which highlights the changes in areal extent of drought of specified severity and duration under current conditions and in each emissions scenario. Finally, avoiding increases in drought would be economically beneficial. Hence, the avoided increases (Figs. 10 to 12, Figs. S18-21) could ultimately be converted to economic benefits, which would contribute to the overall assessment of the benefits of climate policy.

\section{CONCLUSIONS}

The present study is one of the first applications of the CIAS integrated assessment model, and demonstrates its potential for providing policy-relevant information. In particular, our study highlights the significant increases in drought length and frequency expected in the southern parts of Europe in the second half of the 21st century in the absence of climate policy. These findings are consistent with a number of other global and regional studies which are based on different modelling approaches, such as the use of regional climate models driven by GCM outputs, and with recent observations of drying in the region. Significantly, this study has highlighted the high potential for avoidance of the greater part of these changes through emissions reduction, avoiding up to $200 \mathrm{mo}$ of year-long drought or 300 mo of 5 mo drought during 2050-2098 in some areas. The nations benefitting the most are the southern European countries Spain, France and countries surrounding the Mediterranean and Black Seas. Stringent emission reduction scenarios that stabilize $\mathrm{CO}_{2}$ concentrations in the atmosphere at levels of 400 to $450 \mathrm{ppm}$, and which also make reductions in the emissions of $\mathrm{CH}_{4}$ and $\mathrm{N}_{2} \mathrm{O}$, would be necessary to achieve this, according to the projections of future drought shown here. Major benefits accruing from strong mitigation are apparent for all 3 GCM patterns that we used, though we highlight how the locations of the benefits vary between GCM patterns, and note that our results are dependent on the ability of the GCMs to simulate future changes in precipitation reliably.

The present study also highlights the wide range of potential drought climates that adaptation planners currently need to consider in both the first and the 
second halves of the 21st century. For example, in parts of Spain the number of months undergoing year-long drought in a $49 \mathrm{yr}$ period could remain below 50 or increase to over 200 during the 21st century, with the range being due to the uncertainties in climate prediction resulting from the use of various GCMs, as well as the uncertainties in future emissions.

\section{LITERATURE CITED}

Arnell NW (2004) Climate change and global water resources: SRES emissions and socioeconomic scenarios. Glob Environ Change 14:31-52

> Arnell NW, Delaney EK (2006) Adapting to climate change: public water supply in England and Wales. Clim Change 78:227-255

Barker T, Pan H, Kohler J, Warren R, Winne S (2006) Avoiding dangerous climate change by inducing technological progress: scenarios using a large-scale econometric model. In: Schellnhuber HJ, Cramer W, Nakicenovich N, Wigley T, Yohe G (eds) Avoiding dangerous climate change. Cambridge University Press, Cambridge, p 361-372

> Beniston M, Stephenson DB, Christensen OB, Ferro CAT and others (2007) Future extreme events in European climate: an exploration of regional climate model projections. Clim Change 81(Suppl 1):71-95

Betts RA, Cox PM, Lee SE, Woodward FI (1997) Contrasting physiological and structural vegetation feedbacks in climate change simulations. Nature 387:796-799

> Blenkinsop S, Fowler HJ (2007a) Changes in drought frequency, severity and duration for the British Isles projected by the PRUDENCE regional climate models. J Hydrol (Amst) 342:50-71

Blenkinsop S, Fowler HJ (2007b) Changes in European drought characteristics projected by the PRUDENCE regional climate models. Int J Climatol 27:1595-1610

Burke EJ, Brown SJ, Christidis N (2006) Modeling the recent evolution of global drought and projections for the twenty-first century with the Hadley Centre climate model. J Hydrometeorol 7:1113-1125

Christensen JH, Carter TR, Rummukainen M, Amanatidis G (2007) Evaluating the performance and utility of regional climate models: the PRUDENCE project. Clim Change $81: 1-6$

COSMIC (1997) Country specific model for intertemporal climate. http://unfccc.int/adaptation/nairobi_work_pro gramme/knowledge_resources_and_publications/items/ 5346.php accessed on 17.02.04

Costa AC, Soares A (2009) Trends in extreme precipitation indices derived from a daily rainfall database for the south of Portugal. Int J Climatol 29:1956-1975

European Environment Agency 2007. Climate change and water adaptation issues. EEA Tech Rep No. 2/2007, Copenhagen

> Fowler HJ, Ekstrom M, Blenkinsop S, Smith AP (2007) Estimating change in extreme European precipitation using a multimodel ensemble. J Geophys Res 112:D18104, doi: 10.1029/2007JD008619

Frei C, Scholl R, Fukutome S, Schmidli J, Vidale PL (2006) Future change of precipitation extremes in Europe: inter- comparison of scenarios from regional climate models. J Geophys Res 111:D06105, doi:10.1029/2005JD005965 Fussel HM (2003) The ICLIPS impacts tool: a graphical user interface to climate impact response functions for impacts assessments of climate change. Integrated Assess 4:116-125

> Gao X, Giorgi F (2008) Increased aridity projected in Mediterranean region under greenhouse gas forcing. Global Planet Change 62:195-209

> Gedney N, Cox PM, Betts RA, Boucher O, Huntingford C, Stott PA (2006) Detection of a direct carbon dioxide effect in continental river runoff records. Nature 439:835-838

> Gleckler PJ, Taylor KE, Doutriaux C (2008) Performance metrics for climate models. J Geophys Res 113:D06104. doi:10.1029/2007JD008972

Goodess CM, Osborn TJ, Hulme M 2003. The identification and evaluation of suitable scenario development methods for the estimation of future probabilities of extreme weather events. Tyndall Centre Tech Rep 4, Tyndall Centre, Norwich

Houghton JT, Ding Y, Griggs DJ, Noguer M and others (eds) (2001) Climate change 2001: the scientific basis. Contribution of Working Group I to the Third Assessment Report of the Intergovernmental Panel on Climate Change (IPCC). Cambridge University Press, Cambridge

Hayes MJ, Svoboda MD, Wilhite DA, Vanyarkho OV (1999) Monitoring the 1996 drought using the Standardised Precipitation Index. Bull Am Meteorol Soc 80:429-438

Heim RR (2002) A review of twentieth-century drought indices used in the United States. Bull Am Meteorol Soc 83:1149-1165

Hirabayashi Y, Kanae S, Emori S, Oki T, Kimoto M (2008) Global projections of changing risks of floods and droughts in a changing climate. Hydrol Sci J 53:754-772

Hisdal H, Stahl K, Tallaksen LM, Demuth S (2001) Have streamflow droughts in Europe become more severe or frequent? Int J Climatol 21:317-333

Hulme M, Barrow E (eds) (1997) Climates of the British Isles: present, past and future. Routledge, London

> Hulme M, Raper SCB, Wigley TML (1995) An integrated framework to address climate change (ESCAPE) and further developments of the global and regional climate modules. Energy Policy 23:347-355

Hulme M, Jenkins GJ, Lu X, Turnpenny JR and others (2002) Climate change scenarios for the United Kingdom: the UKCIP02 scientific report. Tyndall Centre for Climate Change Research, School of Environmental Sciences, University of East Anglia, Norwich

IPCC (1994) Climate change 1994: radiative forcing of climate change and an evaluation of the IPCC IS92 emissions scenarios. Cambridge University Press, Cambridge

Kenny GJ, Warrick RA, Mitchell ND, Mullan AB, Salinger MJ (1995) CLIMPACTS: an integrated model for assessment of the effects of climate change on the New Zealand environment. J Biogeogr 22:883-895

> Lehner B, Doll P, Alcamo J, Henrichs T, Kaspar F (2006) Estimating the impact of global change on flood and drought risks in Europe: a continental integrated analysis. Clim Change 75:273-299

> Lloyd-Hughes B, Saunders MA (2002) A drought climatology for Europe. Int J Climatol 22:1571-1592

Marsh TJ (2001) Climate change and hydrological stability: a look at long-term trends in south-eastern Britain. Weather 56:319-328

Marsh T, Cole G, Wilby R (2007) Major droughts in England 
and Wales, 1800-2006. Weather 62:87-93

Meinshausen M, Raper S, Wigley T (2008) Emulating IPCC AR4 atmosphere-ocean and carbon cycle models for projecting global-mean, hemispheric and land/ocean temperatures: MAGICC 6.0. Atmos Chem Phys Discuss 8:6153-6272

Mitchell TD (2003) Pattern scaling: an examination of the accuracy of the technique for describing future climates. Clim Change 60:217-242

Mitchell TD, Jones PD (2005) An improved method of constructing a database of monthly climate observations and associated high-resolution grids. Int J Climatol 25: 693-712

Mitchell TD, Carter TR, Jones PD, Hulme M, New MG (2004) A comprehensive set of high-resolution grids of monthly climate for Europe and the globe: the observed record (1901-2000) and 16 scenarios (2001-2100). Tyndall Centre Working Paper no.55, Tyndall Centre, Norwich

Nakicenovich N, Swart R (2000) Special report on emissions scenarios. Cambridge University Press, Cambridge

New M, Lopez A, Dessai S, Wilby R (2007) Challenges in using probabilistic climate change information for impacts and adaptation decision-making: an example from the water sector. Phil Trans R Soc A 365:2117-2131

Osborn TJ (2009) A user guide for ClimGen: a flexible tool for generating monthly climate data sets and scenarios. Climatic Research Unit, University of East Anglia (available at www.cru.uea.ac.uk/ timo/climgen/ClimGen_v102_userguide_2feb2009.pdf)

> Palmer TN, Ralsanen J (2002) Quantifying the risk of extreme seasonal precipitation events in a changing climate. Nature 415:512-514

Planton S, Deque D, Chauvin F, Terray L (2008) Expected impacts of climate change on extreme climate events. C R Geosci 340:564-574

Editorial responsibility: Mikhail Semenov, Harpenden, UK
Raisanen J (1994) A comparison of the results of seven GCM experiments in northern Europe. Geophysica 30:3-30

Rotmans J, Hulme M, Downing TE (1994) Climate change implications for Europe: an application of the ESCAPE model. Glob Environ Change 4:97-124

Sheffield J, Wood EF (2008) Projected changes in drought occurrence under future global warming from multimodel, multi-scenario, IPCC AR4 simulations. Clim Dyn 31:79-105

Sillmann J, Roeckner E (2008) Indices for extreme events in projections of anthropogenic climate change. Clim Change 86:83-104

Tebaldi C, Hayhoe K, Arblaster JM, Meehl GA (2006) Going to the extremes: an intercomparison of model-simulated historical and future changes in extreme events. Clim Change 79:185-211

> Tolika K, Maheras P, Flocas HA, Arseni-Papadimitrou A (2006) An evaluation of a general circulation model (GCM) and the NCEP-NCAR reanalysis data for winter precipitation in Greece. Int J Climatol 26:935-955. doi: 10.1002/joc.1290

> Trigo RM, Palutikof JP (2001) Precipitation scenarios over Iberia: a comparison between direct GCM output and different downscaling techniques. J Clim 14:4422-4446

> Warren R, de la Nava Santos S, Arnell NW, Bane M and others (2008). Development and illustrative outputs of the Community Integrated Assessment System (CIAS), a multi-institutional modular integrated assessment approach for modelling climate change. Environ Model Software 23:592-610

Weiss M, Florke M, Menzel L, Alcamo J (2007) Model-based scenarios of Mediterranean droughts. Adv Geosci 12: 145-151

Wigley TML, Raper SCB (2001) Interpretation of high projections for global-mean warming. Science 293:451-454

Submitted: September 23, 2010; Accepted: August 15, 2011

Proofs received from author(s): January 6, 2012 